\title{
Cellular Secretion
}

National Cancer Institute

\section{Source}

National Cancer Institute. Cellular Secretion. NCI Thesaurus. Code C17119.

Production by a cell or aggregation of cells (a gland) of a physiologically active substance and its movement out of the cell or organ in which it is formed. Discharge across the cell membrane, into the intracellular space or ducts, of endogenous substances resulting from the activity of intact cells of glands, tissues, or organs. 